Convened by the Coregonid Steering Committee, with membership from U.S. Fish and Wildlife Service and U.S. Geological Survey, on October 11-13, 2016

\title{
Report from the Workshop on Coregonine Restoration Science
}

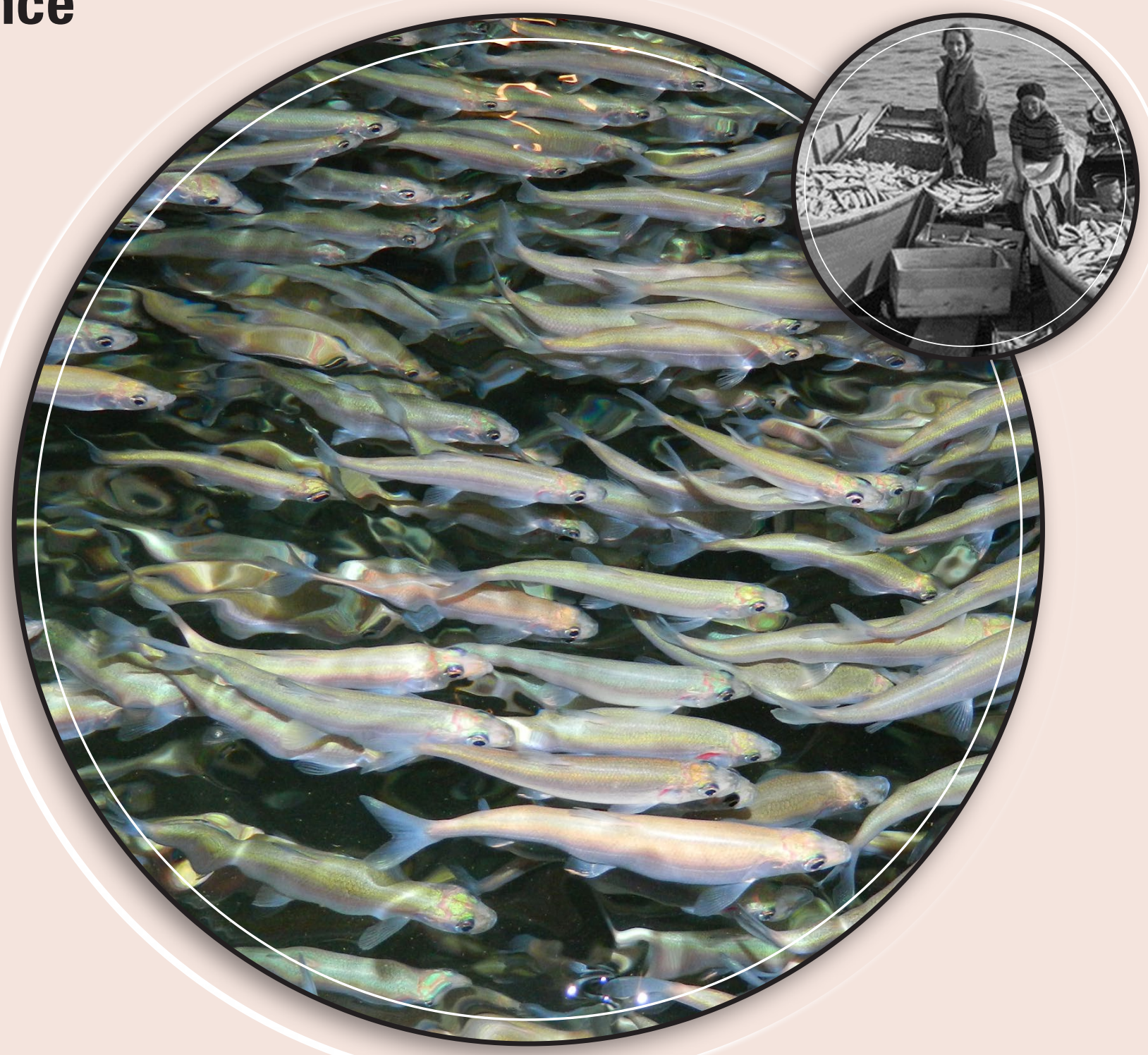

Open-File Report 2017-1081

U.S. Department of the Interior

U.S. Geological Survey 


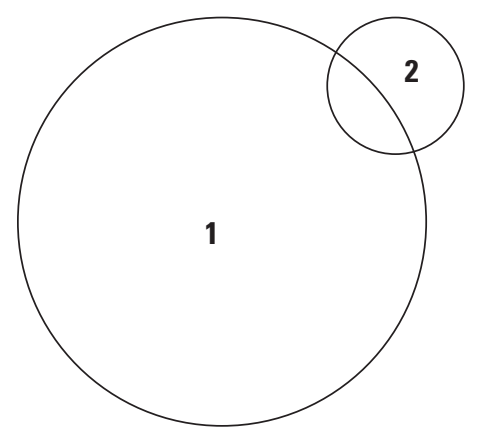

Cover. 1. Bloater (Coregonus hoyi) being cultured at Harwood Fish Culture Station, Ontario. Photograph courtesy of Ontario Ministry of Natural Resources and Forestry. 2. Cisco (Coregonus artedi) being harvested from Lake Superior in the early 1900s. Photograph courtesy of North Shore Commercial Fishing Museum. 


\section{Report from the Workshop on Coregonine Restoration Science}

By Charles R. Bronte, David B. Bunnell, Solomon R. David, Roger Gordon, Dimitry

Gorsky, Michael J. Millard, Jennifer Read, Roy A. Stein, and Lynn Vaccaro

Convened by the Coregonid Steering Committee, with membership from

U.S. Fish and Wildlife Service and U.S. Geological Survey, on

October 11-13, 2016

Open-File Report 2017-1081 


\title{
U.S. Department of the Interior \\ RYAN K. ZINKE, Secretary
}

\section{U.S. Geological Survey William H. Werkheiser, Acting Director}

\author{
U.S. Geological Survey, Reston, Virginia: 2017
}

For more information on the USGS - the Federal source for science about the Earth, its natural and living resources, natural hazards, and the environment-visit http://www.usgs.gov/ or call 1-888-ASK-USGS.

For an overview of USGS information products, including maps, imagery, and publications, visit http://store.usgs.gov/.

Any use of trade, firm, or product names is for descriptive purposes only and does not imply endorsement by the U.S. Government.

Although this information product, for the most part, is in the public domain, it also may contain copyrighted materials as noted in the text. Permission to reproduce copyrighted items must be secured from the copyright owner.

Suggested citation:

Bronte, C.R., Bunnell, D.B., David, S.R., Gordon, Roger, Gorsky, Dimitry, Millard, M.J., Read, Jennifer, Stein, R.A., and Vaccaro, Lynn, 2017, Report from the Workshop on Coregonine Restoration Science: U.S. Geological Survey Open-File Report 2017-1081, 23 p., https://doi.org/10.3133/ofr20171081.

ISSN 2331-1258 (online) 


\section{Foreword}

The workshop was organized by the U.S. Geological Survey and the U.S. Fish and Wildlife Service with funding provided by the U.S. Environmental Protection Agency through the Great Lakes Restoration Initiative. Although this report is the authors' compilation of the material presented and discussed at the workshop, its content is more accurately described as the product of the combined thinking of workshop participants. Resultant uncertainties are opinions developed within the workshop and are not the final statement or policy position of the agencies involved. 


\section{Acknowledgments}

We thank Roy A. Stein for his excellent facilitation of the workshop. Wendy Stott and Michael Hansen provided helpful comments to improve the clarity of this report. 


\section{Contents}

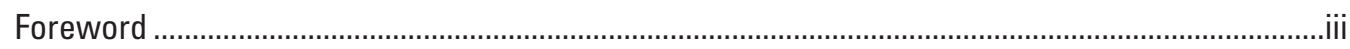

Acknowledgments ….......................................................................................................................

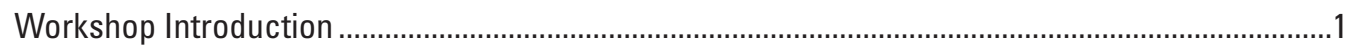

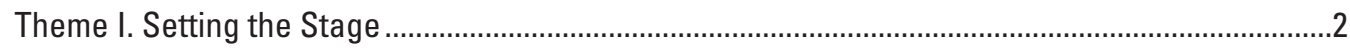

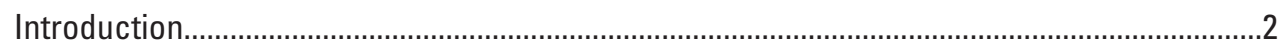

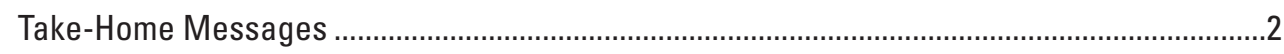

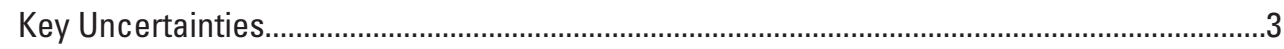

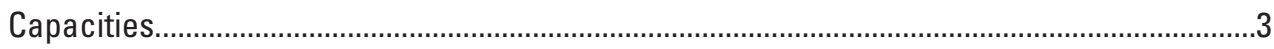

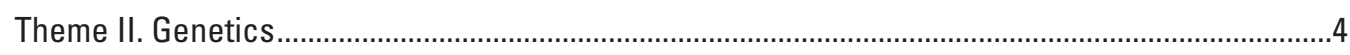

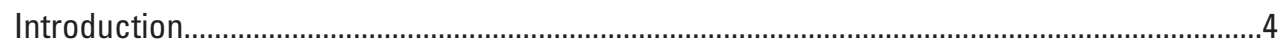

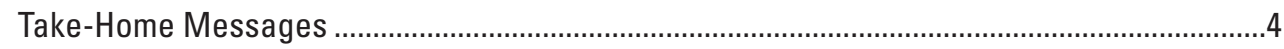

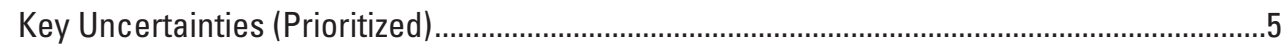

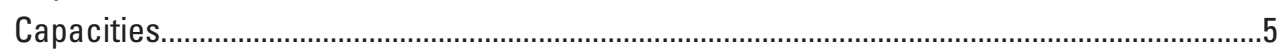

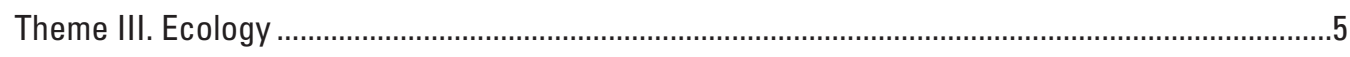

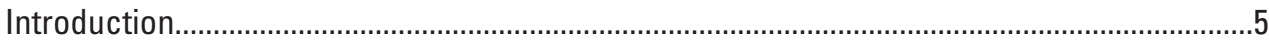

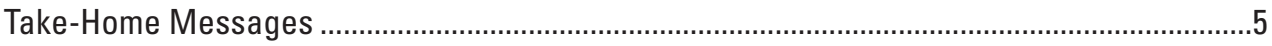

Key Uncertainties (Prioritized) ................................................................................................

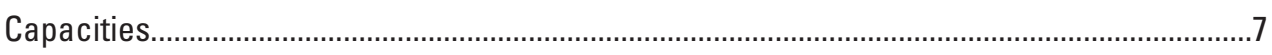

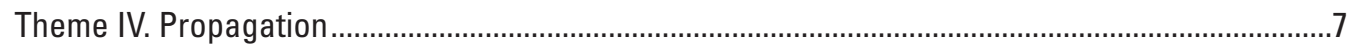

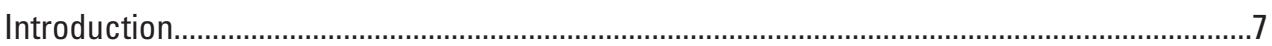

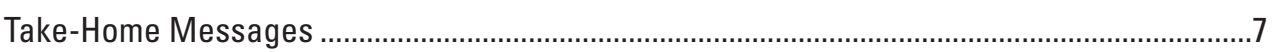

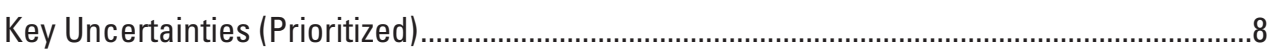

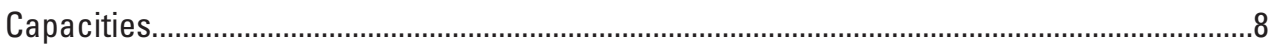

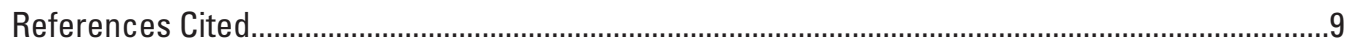

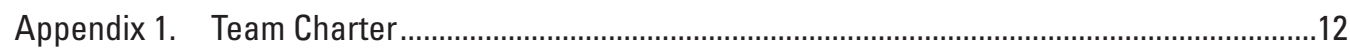

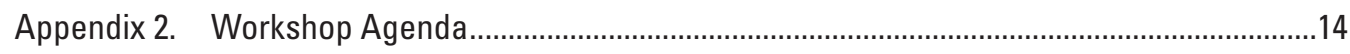

Appendix 3. Workshop Participants........................................................................................17

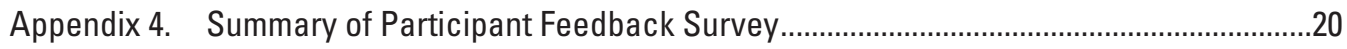

\section{Table}

1. Summary of 21 respondents to postworkshop survey on potential topics for future workshops that considered each topic to be of high, medium, or low importance (ranked from highest to lowest) 


\section{Abbreviations}

CLC Council of Lake Committees

DOI U.S. Department of Interior

FWS U.S. Fish and Wildlife Service

GLFC Great Lakes Fishery Commission

OMNRF Ontario Ministry of Natural Resources and Forestry

USGS U.S. Geological Survey 


\title{
Report from the Workshop on Coregonine Restoration Science
}

\author{
By Charles R. Bronte', David B. Bunnell2, Solomon R. David², Roger Gordon³, Dimitry Gorsky4, Michael J. \\ Millard ${ }^{5}$, Jennifer Read ${ }^{6}$, Roy A. Stein ${ }^{7}$, and Lynn Vaccaro ${ }^{3}$
}

\section{Workshop Introduction}

Great Lakes fishery managers have the opportunity and have expressed interest in reestablishing a native forage base in the Great Lakes consisting of various forms and species within the genus Coregonus. This workshop was focused on a subset of the genus, and herein we use the term "coregonines" to refer to several species of deepwater ciscoes (also known as "chubs") and the one more pelagic-oriented cisco species (Coregonus artedi, also known as "lake herring"). We also used their species, rather than common, names (for example, C. hoyi instead of bloater) as a matter of convenience, but not because nomenclature has been resolved (Eshenroder and others, 2016). As the principal conservation agency for the United States Government, the Department of Interior (DOI) has unique and significant authorities and capacities to support a coregonine reestablishment program in the Great Lakes. To identify and discuss key uncertainties associated with such a program and develop a coordinated approach, the U.S. Fish and Wildlife Service (FWS) and the U.S. Geological Survey (USGS), the principal DOI bureaus to address Great Lakes fishery issues, held the first of a series of workshops on coregonine science in Ann Arbor, Michigan, on October 11-13, 2016.

Workshop participants included more than 40 DOI personnel and experts invited from academia, the Great Lakes Fishery Commission (GLFC), and the Ontario Ministry of Natural Resources and Forestry (OMNRF). The workshop was organized and developed by a Planning Team under the direction of a Steering Committee (see appendix 3). The workshop

\footnotetext{
${ }^{1}$ U.S. Fish and Wildlife Service, Green Bay Fish and Wildlife Conservation Office.

${ }^{2}$ U.S. Geological Survey, Great Lakes Science Center.

${ }^{3}$ U.S. Fish and Wildlife Service, Jordan River National Fish Hatchery.

${ }^{4}$ U.S. Fish and Wildlife Service, Lower Great Lakes Fish and Wildife Conservation.

${ }^{5}$ U.S. Fish and Wildlife Service, Northeast Fishery Center.

${ }^{6}$ University of Michigan, Water Center.

${ }^{7}$ Ohio State University, Aquatic Ecology Laboratory.
}

was facilitated by Roy Stein, Professor Emeritus at the Ohio State University. Logistical support and organizational advice were provided by Lynn Vaccaro and Jennifer Read from the University of Michigan Water Center.

Workshop objectives (appendix 1) were to identify (1) perceived key uncertainties associated with coregonine restoration in the Great Lakes and (2) DOI capacities for addressing these key uncertainties. The workshop was organized around four themes: Setting the Stage, Genetics, Ecology, and Propagation. This document is organized by these themes. Summaries of presentations and discussions including take-home messages, key uncertainties, and DOI capacities are provided for each theme.

Several possible topics for future workshops were voiced during this initial workshop. A survey was sent to all workshop attendees to gather feedback on how to prioritize future workshop topics (see appendix 4 for details). Table 1 reports that conservation ecology or conservation planning and framework development should be considered for future workshop topics.

Table 1. Summary of 21 respondents to postworkshop survey on potential topics for future workshops that considered each topic to be of high, medium, or low importance (ranked from highest to lowest).

\begin{tabular}{lccc}
\hline \multicolumn{1}{c}{ Potential workshop topic } & High & Medium & Low \\
\hline $\begin{array}{l}\text { Coregonine ecology (early life history, } \\
\text { habitat) }\end{array}$ & 16 & 5 & 0 \\
$\begin{array}{l}\text { Conservation planning and framework } \\
\text { development }\end{array}$ & 14 & 6 & 1 \\
$\begin{array}{l}\text { Coregonine propagation issues } \\
\text { Multifocus workshop (combining theme- }\end{array}$ & 9 & 8 & 4 \\
$\quad$ specific and integrated sessions) & 8 & 10 & 3 \\
$\begin{array}{l}\text { Coregonine genetics (including marker } \\
\text { types, nomenclature) }\end{array}$ & 8 & & 0 \\
$\begin{array}{l}\text { Fish community modeling } \\
\text { Broad DOI collaboration workshop (en- } \\
\text { gaging greater diversity of agencies) }\end{array}$ & 4 & 8 & 9 \\
\hline
\end{tabular}




\section{Theme I. Setting the Stage}

\section{Introduction}

The introductory Setting the Stage theme sought to (1) present the rationale for the workshop and its expected products, (2) set a broader context for this work by exploring previous Salvelinus namaycush (lake trout) restoration efforts in the Great Lakes, and (3) discuss current management priorities related to coregonines across the Great Lakes. To that end, the workshop was kicked off by a presentation from David Bunnell (USGS) to lay out the internal and external motivation for the workshop while reviewing pertinent restoration considerations. Charles Krueger (Michigan State University) then enumerated lessons learned from lake trout restoration, and John Dettmers (GLFC) reviewed questions and priorities currently emerging from Great Lakes fishery managers.

\section{Take-Home Messages}

The presentations showcased the growth of scientific appreciation for the critical role that coregonines historically played in Great Lakes food webs. Deepwater ciscoes (for example, C. kiyi, C. hoyi) connect benthic (habitat associated with the bottom of the lake) and pelagic (habitat associated with open water of the lake) food webs through diel vertical migrations, whereas $C$. artedi transfers energy horizontally between nearshore and offshore communities during spawning migrations. Finally, compared to Alosa pseudoharengus (alewives), coregonines serve as low-thiaminase prey fish for lake trout.

Current food web changes may make the Great Lakes more hospitable to coregonines, thereby creating a unique opportunity to pursue their restoration. Reduced pelagic productivity and increased benthic biomass enhance the role of coregonines in energy transfer. Declines in nonnative alewife and Osmerus mordax (rainbow smelt) increase the probability that coregonines could fill a bentho-pelagic offshore niche.

Coregonines historically supported a vibrant fishery, and interest in restoring coregonines is growing among fishery managers and anglers. John Dettmers outlined current coregonine activities of fishery managers and their lake committeespecific issues.

- The Lake Superior Committee is concerned about C. artedi overharvest. They operate to maintain existing coregonine diversity and seek to better understand trophic linkages, recruitment dynamics, and sustainable stock sizes.

- The Lake Michigan Committee formed a Native Planktivore Task Group in 2013 to scope the feasibility of restoring native planktivores given the current state of the lake ecosystem. This includes a synthesis of genetic considerations and possible impediments to reintroduction.

- The Lake Huron Committee approved experimental stocking of $C$. artedi into Saginaw Bay, with gamete collection from northern Lake Huron C. artedi beginning in November 2016. Lake Huron anglers have concluded that $C$. artedi could occupy the niche that was once filled by alewife.

- The Lake Erie Committee is considering a draft plan for $C$. artedi rehabilitation. They are no longer concerned about potential impacts to the small, existing C. artedi stocks following publication of Eshenroder and others (2016). One issue to resolve is how a rehabilitated population of $C$. artedi could affect rainbow smelt, which currently sustains a commercial fishery and is prey for Sander vitreus (walleye) and lake trout.

- The Lake Ontario Committee has overseen stocking of approximately 500,000 C. hoyi and 285,000 C. artedi since 2012. The $C$. hoyi were raised in Canadian and United States facilities, and derived from gametes collected from Lake Michigan. The $C$. artedi were raised in U.S. facilities and were derived from gametes collected from Chaumont Bay, Lake Ontario.

Dettmers concluded by stating that managers appreciate sound scientific advice along with a clear message about which uncertainties are most important and why some managementrelevant scientific questions cannot be answered at this time.

The 65-year-old lake trout restoration program was outlined by Charles Krueger and provides lessons relevant to coregonine rehabilitation initiatives. For example, before developing a restoration plan, current knowledge of life history and ongoing impediments to population growth should be assessed (see Dunham and others, 2011). Krueger noted that after many years of stocking lake trout in the Great Lakes, natural reproduction could not be detected in many lakes. Impediment analyses identified several potentially limiting factors, including inability to locate spawning grounds, insufficient spawners, predation on lake trout eggs and larvae, stocking of maladapted stocks, Petromyzon marinus (sea lamprey) predation, water quality, habitat degradation, and infertile eggs caused by thiamine deficiency. Many of these impediments have been reduced over time by management efforts, such as sea lamprey control and more effective stocking practices. Ongoing ecosystem and fish community changes, such as declining alewife populations and better control of mortality, also accelerated lake trout restoration, although success varied among lakes. For example, alewives prey on lake trout larvae and contribute to thiamine deficiency and infertility of adult lake trout. Declining alewife populations in Lake Huron, combined with increasing lake trout parental stocks (resulting from reduced sea lamprey and fishing mortality), likely allowed lake trout to reestablish successful natural reproduction. 
Experiences with lake trout restoration reveal that genetic origin and age of stocked fish can influence outcomes. Like coregonines, lake trout exhibit diversity in morphology, habitat use, and diet, which likely contribute to their resilience. Lake trout stocking programs historically have focused on the shallow-water or lean form, although most lakes also had deepwater forms that were later considered for stocking. Lake trout from some geographic sources (for example, Seneca Lake) survived better than others, contributing more to wild recruitment than other strains. The lake trout program may have benefited from more systematic experimentation with stocking different life stages or morphologies, such as adult transfers from Lake Superior.

Krueger offered 12 key lessons for fish restoration, emphasizing coordination across agencies, stakeholder engagement, and use of multiple actions (for example, fishing regulations, stocking, habitat protection, stock assessments, sea lamprey control) to maximize the likelihood of success. Aggressive sea lamprey control, commercial fishery closures, and coordinated evaluation programs are critical for lake trout rehabilitation programs. Essential aspects of the programs include clear restoration goals, interim population objectives and timetables, and comprehensive monitoring. Also essential are specific opportunities to revisit restoration objectives and implementation strategies.

\section{Key Uncertainties}

Workshop participants identified a number of highpriority issues related to coregonine restoration. A synthesis of existing research and well-coordinated new research could help address questions related to each stage of restoration planning using an adaptive management framework to guide experimentation. Unlike the other three themes, the following issues are not amenable to prioritization, because each is equally critical to a successful program.

- Goal Setting: What does a restored coregonine community look like in each lake? Which forms existed historically, and which extant forms should be the focus of restoration in the context of meeting management objectives, such as filling a particular ecosystem function?

- Problem Identification: Are impediments to reestablishment and growth sufficiently understood? Is current knowledge effectively summarized to choose appropriate and successful restoration actions and conservation targets?

- Restoration Protocols: How can stocking and other programs be best designed to meet management objectives? For example, how many fish would be needed in which locations to efficiently test and improve stocking success while simultaneously meeting objectives over a specified time period?

- Evaluation: How can research and assessment be best coordinated and targeted to track dynamics in small populations; address knowledge gaps in coregonine life history, genetics, and propagation; and support a robust adaptive management process?

\section{Capacities}

The USGS Great Lakes Science Center and FWS Regions 3 and 5 can assist with restoration planning in a variety of ways.

- Assessment: USGS and FWS conservation offices annually conduct fish community surveys, some in collaboration with other agencies, to inform managers' understanding of current coregonine populations over time. For example, USGS deep-water trawl and joint USGS/FWS/State hydroacoustic surveys serve to assess $C$. hoyi and C. artedi stocks in Lakes Superior, Michigan, and Huron, and C. kiyi and C. zenithicus stocks in Lake Superior.

- Planning Frameworks: The FWS has developed a number of conservation planning tools and has experience developing strategic habitat conservation and adaptive management programs for other species and ecosystems. FWS could apply these to coregonines while working in partnership with GLFC-supported lake committees. Even with these intellectual capabilities, DOI science capacity would be enhanced with the addition of a scientist with specific expertise in restoration ecology.

- Coregonine Biology: The USGS and FWS have several research fishery biologists who have extensively studied coregonines, including the exploration of different forms, current and historical distributions, genetics, and their life history. FWS also has experts with experience working with gamete collections and fertilization; fish culture; broodstock development and hatchery production; and working with egg, larval, and adult life stages of coregonine populations.

- Fish Ecology: Fish ecologists and geneticists from the USGS and FWS can assist with evaluations of current impediments for extant coregonines in lakes to identify historically and ecologically appropriate forms and source populations to meet different management objectives (for example, filling specific ecosystem functions). 


\section{Theme II. Genetics}

\section{Introduction}

In this theme, participants sought to gain a shared understanding of (1) leading and competing hypotheses of coregonine evolution in lakes throughout North America and (2) genetic implications for reintroduction efforts. Presentations in this theme were made by Julie Turgeon (Université Laval) and Wendy Stott (Michigan State University) that provided updates on their recently published and ongoing research on coregonine genetics.

Early 20th century biologists named eight different species of deepwater ciscoes, plus the more pelagic oriented C. artedi in the Great Lakes based on morphological differences (Koelz, 1929). However, genetic and morphological research over the past decades has, thus far, revealed little correspondence between genetics and morphology within North American coregonines. When genetic differentiation can be determined, groupings generally conform to differences in geography rather than taxonomic designations (Turgeon and Bernatchez (2003). Coregonines also can be textbook examples of fish genetics interacting with the local environment to produce great phenotypic plasticity (Lindsey, 1981). Turgeon and Bernatchez (2003) state, "Our results revealed a complex evolutionary history marked by postglacial reticulation events coupled with recent and independent evolution of similar phenotypes." They further suggested that a single generic taxon should be used for all forms, and recommend calling them $C$. artedi because this is the ancestral form, a conclusion further supported by their more recent work (Turgeon and others, 2016).

As managers seek to restore the morphological and functional diversity of coregonines in lakes where large-scale extirpations have occurred, reintroductions of these forms will require either stocking of hatchery-reared young from gametes collected from extant populations from other lakes or potentially translocating fish from extant populations. At present, C. hoyi is being stocked into Lake Ontario from gamete sources in Lake Michigan, a strategy similar to that used for lake trout restoration throughout the Great Lakes (with the exception of Lake Superior). When reintroductions occur in lakes where forms have been extirpated, the only relevant genetics consideration is trying to reintroduce a form that is genetically similar to what was lost.

For lakes where smaller populations still exist, such as $C$. artedi in Lakes Ontario, Huron, and Michigan, some debate exists among and within agencies on the risk of using gametes from either within-lake sources or using from larger populations elsewhere. Within-lake sources carry the risks of inbreeding depression and inability of small populations to withstand large gamete collections. Bringing in fish from other lakes carries risks such as outbreeding depression. The risk of inbreeding depression can be minimized by establishing and adhering to appropriate hatchery protocols. The decision to use gametes from genetically diverse populations in other lakes is also termed "evolutionary rescue" (Vander Wal and others, 2012) and generally occurs when within-lake source populations are small, declining in abundance, or have low genetic diversity. Evolutionary rescue assumes that increased genetic diversity will improve fitness. However, outbreeding depression could occur if offspring resulting from the mixing of gene pools are less fit than the "rescued" population.

In lakes with smaller existing populations, one stocking risk factor is the intensity of stock-isolating mechanisms during reproduction within a given lake. For example, recent genetic research by Stott indicates some divergence among small populations of nearshore-spawning forms of $C$. artedi in northern Lake Huron and Lake Michigan, which, in turn, suggests some stock isolating mechanism, like natal homing, may be at work. In contrast, the genetic results for the larger Lake Superior population of $C$. artedi do not show signs of stock structuring, which suggest that natal homing is not prevalent.

\section{Take-Home Messages}

The following are key take-home messages from the presentations.

- Since glaciation, coregonine forms have diverged independently and repeatedly in each lake, making each form in each lake unique. Any form is genetically more similar to a different form found in the same lake than to the same form found in another lake. Hence, forms are generally of recent, local origin.

- Genetic differentiation among forms is very difficult to discern using neutral markers. Within forms, genetic differentiation among sites (or lakes) is far more difficult to discern than for most other species in the Great Lakes (for example, Acipenser fulvescens Rafinesque [lake sturgeon], Coregonus clupeaformis [lake whitefish]). Possible causes for lack of differentiation include extremely high phenotypic plasticity from one gene pool or incomplete genetic drift among multiple gene pools (owing to weak reproductive isolation).

- From neutral markers, we know genetic diversity of extant $C$. artedi across Great Lakes sites is similar (that is, heterozygosity, allelic richness, allelic variance), with the exception of $C$. artedi in Grand Traverse Bay, Mich., Lake Michigan, where there is less heterozygosity (that is, fewer alleles). Genetic differences among sites are small, but statistically significant; however, the ecological or biological significance of these genetic differences is unclear. The most important differences were that (1) Lake Ontario C. artedi populations are distinct from the upper Great Lakes, and (2) Lake Michigan Grand Traverse Bay C. artedi population is also distinct from all other sites. 
- Genetic and phenotypic (or morphological) differences are not closely correlated. Hence, any linkage between genetic differentiation and ecological function is unclear.

\section{Key Uncertainties (Prioritized)}

Workshop participants prioritized the following uncertainties surrounding genetics through breakout group discussion and individual voting.

1. Managers and policy makers have limited understanding of the evolutionary history of coregonines, as well as how coregonines differ from other fish species (such as lake sturgeon) that have well-developed stock-isolating mechanisms (homing, distinct habitat selection and use). This limited understanding has implications for selecting the best source populations for reintroductions. Clear, understandable language in presentations to the Council of Lake Committees would assist in making informed decisions about reintroduction options and potential source populations.

2. Can genetic tools using neutral or functional regions of the genome be developed to distinguish among forms of coregonines (non-C. artedi from C. artedi) and among forms within $C$. artedi? These tools would be useful for detecting presence or absence of target and nontarget forms in larval fish surveys, as well as detecting offspring of stocked versus wild fish, which is a critical need in any stocking evaluation.

3. What are the roles of genetics and environment on the development of phenotype and the extent of plasticity? This uncertainty could be addressed by designing and completing "common garden experiments," where different forms are reared under identical conditions to separate genetic from environment influence on phenotypic expression.

4. Can the hybrid swarm hypothesis (Eshenroder and others, 2016) for Lake Huron be evaluated through genetics? Does the function of the extant Lake Huron hybrid swarm differ from the ancestral forms (that is, C. hoyi)? Might the Lake Huron hybrid be a good candidate for reintroduction to other lakes? Comparing genetics and stable isotopes of existing $C$. hoyi in Lake Huron to museum specimens of coregonine forms would address this uncertainty.

\section{Capacities}

The USGS, FWS Region 3, and FWS Region 5 all have trained geneticists, technical support staff, and laboratory capacities. These DOI agencies within the Great Lakes can also collaborate with established partnerships at universities or with other agency geneticists outside the Great Lakes. The USGS has experimental rearing capacities in Ann Arbor, Mich., Hammond Bay, Mich., and Cortland, New York, that can be used on these and other applied research questions (for example, for common garden experiments). The USGS also possesses database management capabilities to store, manage, and retrieve large field and lab datasets. All three DOI entities have the technical capability to sample existing and reintroduced populations with large and small research vessels equipped with bottom and mid-water trawls, ichthyoplankton nets, and graded-mesh gill nets. Partnering with academic institutions will assist the DOI in pursuing some genetic questions, such as identifying genetic markers that code to specific regions of the genome that may have particular functional relevance.

\section{Theme III. Ecology}

\section{Introduction}

In this theme, we sought to (1) achieve a shared understanding of the distribution, abundance, form, and function of coregonines of the Great Lakes and (2) describe factors that are hypothesized to limit recruitment, growth, and survival of the more well-studied forms, such as $C$. artedi and C. hoyi. To that end, the theme featured three presentations. Andrew Muir (GLFC) described important findings from a recently published monograph on the status of $C$. artedi and deepwater ciscoes in the Great Lakes (Eshenroder and others, 2016). Mark Vinson (USGS) synthesized current knowledge about potentially important mechanisms underlying recruitment dynamics of $C$. artedi and C. hoyi in the Great Lakes. Randy Eshenroder (GLFC) completed the presentations by laying out his hypothesis describing three different ecomorphotypes of C. artedi: typical form, as well as true and false albus forms. One common theme emerging from the talks was that addressing key uncertainties in coregonine restoration ecology will vary by lake, form, and "restoration unit" (the area where restoration takes place, such as lake, bay, or reef).

\section{Take-Home Messages}

The following are key take-home messages from the presentations.

- A newly published monograph by Eshenroder and others (2016) outlines the status of deepwater ciscoes and C. artedi. It reveals that of the 15 major forms assumed extant in the basin by Todd and Smith (1992), 12 remain, 2 have been lost to introgression (Lake Huron), and 1 is considered extirpated (Lake Erie). 
- Reestablishing coregonines in the Great Lakes will restore lost genetic diversity and ecological function, particularly energy and nutrient cycling between benthic and pelagic zones and between littoral and profundal zones.

- Muir demonstrated a statistical relationships between $\delta^{13}$ carbon (an indicator of where food is consumed) and measures of coregonine body shapes and gill raker spacing. This indicates the morphology of coregonines does correspond to its functional role within the food web.

- Eshenroder and others (2016) proposed that C. artedi populations within the Great Lakes are comprised of three ecomorphotypes.

- The most common was named $C$. artedi by Koelz (1929) and is often referred to as typical C. artedi. This ecomorphotype is shallow-bodied, highly migratory, and was the predominant form in Lakes Michigan, Huron, and Ontario, and it remains the most common form in Lake Superior. Typical $C$. artedi from different Great Lakes are morphologically indistinguishable.

- The second ecomorphotype of $C$. artedi, provisionally named true albus (named albus by Koelz), was predominant in Lake Erie and less common in Lakes Superior and Ontario. It is morphologically similar to typical $C$. artedi, except for being deeper bodied. Like typical $C$. artedi, this true albus was migratory and is presumed to have existed as a metapopulation, at least in Lakes Erie and Ontario, where it spawned in deep water.

- Eshenroder proposed a third ecomorphotype of C. artedi, provisionally naming it false albus, because it was not described by Koelz. False albus spawns in shallow water in bays and occurs contemporaneously as relatively nonmigratory populations in Lakes Michigan and Huron. Morphologically, false albus is dissimilar to both typical and true albus because it has a deeper body, shorter head, smaller eye, shorter paired fins.

- Improved understanding of the ecology and life history (especially reproductive and early life stage biology) of $C$. artedi and all deepwater forms is necessary to inform restoration efforts.

- Vinson described how recruitment patterns of C. artedi in Lake Superior and C. hoyi in Lake Michigan are variable, but appear to be somewhat synchronous among lakes and across pelagic and deepwater cisco populations. Several factors likely contribute to recruitment dynamics such as spawner abundance, sex ratio, adult condition, predation on early life history stages, zooplankton prey for larval fish, climatic factors including ice, water temperature, and wind.

- The ability to identify larval and juvenile forms of coregonines is critical for improved understanding of recruitment and population dynamics. Previous research suggests that the larval and early juvenile period (between early summer and early fall) may be critical for setting year-class strength.

\section{Key Uncertainties (Prioritized)}

Workshop participants prioritized the following uncertainties surrounding ecology through breakout group discussion and individual voting.

1. What is the quality and distribution of nearshore and pelagic spawning habitats, past and present? What are the specific characteristics of these habitats and associated coregonine spawning behavior? To address these uncertainties, new vessel surveys would be needed to sample potential spawning habitats during coregonine spawning periods. Advanced technologies (for example, acoustics, autonomous underwater vehicle [AUV]) could substantially contribute to habitat evaluation, especially so given the presence of ice during spawning.

2. How many fish should be stocked, and at which life stage? Might these targets vary by lake or by habitat? Stock-recruit models exist for $C$. artedi in Lake Superior and $C$. hoyi in Lake Michigan and can inform stocking targets for other lakes. Propagation research also can inform which life stages can be produced for stocking.

3. Where are age- 0 coregonines during summer through fall, the period that is likely critical for year-class formation? What ecological mechanisms drive mortality during this period? To develop an answer to this question, age- 0 coregonines must be identified by form. Is this possible via genetics? As with Key Uncertainty 1, above, additional surveys are required to identify habitat and estimate abundance and mortality of age- 0 coregonines during this potentially critical period.

Other uncertainties captured during Day 2 breakouts (no prioritized order):

- What is the migratory behavior of C. artedi? How does it vary among $C$. artedi ecomorphotypes?

- Can we identify potential refuges for existing populations (assuming fisheries account for significant mortality)?

- What are existing abiotic and biotic impediments to restoration that can inform propagation decisions?

- What are potential effects of existing predators and exotic planktivores on coregonines, including stocked fish? 
- Do coregonines imprint on specific habitats, and if so, at what stages?

- What role does habitat play in limiting coregonine populations? Do differences in habitat preference exist between pelagic and deepwater ciscoes, or between different ecomorphotypes of $C$. artedi?

\section{Capacities}

Intellectual capacity exists in both the USGS and FWS to address key uncertainties associated with coregonine restoration ecology. However, agency leaders should provide guidance on how scientists should prioritize these new research efforts relative to other, ongoing initiatives. USGS and FWS vessels can survey coregonine spawning and habitat but are limited to seasons when lakes are free of ice. New technologies such as acoustic arrays or AUVs might overcome some vessel or survey limitations. Stock-recruit models exist for C. artedi in Lake Superior and C. hoyi in Lake Michigan and can inform targets for other lakes and forms. M. Bartron and W. Stott are developing DNA barcoding techniques to identify different forms of Great Lakes coregonines across life stages. The USGS and FWS also have research laboratory capacities to complement ecology and life history field studies.

\section{Theme IV. Propagation}

\section{Introduction}

This theme sought to increase understanding of (1) characteristics of coregonine stocking success elsewhere (presentation by Chuck Bronte, FWS) and (2) challenges of ongoing coregonine propagation in the Great Lakes (presentations by Roger Gordon [FWS], Trevor Pitcher [University of Windsor], and Kevin Loftus [OMNRF]). Current propagation efforts support requests from the State of New York and the Province of Ontario for C. hoyi and C. artedi to be stocked in Lake Ontario and from the Lake Huron Committee to stock C. artedi in Saginaw Bay, Lake Huron. Propagation and stocking are the most practical ways to reintroduce extirpated forms (that is, C. kiyi in Lakes Michigan and Huron) within reasonable time periods.

\section{Take-Home Messages}

The following are key take-home messages from the talks.

- In a retrospective analysis of global studies to determine the characteristics associated with coregonine stocking success, several generalities emerged.
- Success is higher in smaller lakes, so long as stocking occurs with at least summer fingerling (or older) life stages.

- Greatest success occurs when stocking occurs for $>10$ years.

- Greatest success occurs when the species is extant in the stocked water body (that is, stock enhancement).

- Hatcheries should aim to maximize survival of stocked fish rather than focusing a production target that does not explicitly consider survival.

- With approximately 5 years of experience propagating C. hoyi from wild gametes from Lake Michigan, hatcheries have achieved fast growth and high survival in captivity, but poststocking growth and survival are unknown.

- Methods for C. artedi propagation are well-established in the region (relative to $C$. hoyi), but factors influencing poststocking survival remain unknown.

- To meet desired output of C. hoyi, broodstock development may be necessary to supplement collection of wild gametes. The $C$. hoyi have been reared to adults in hatcheries, but challenges must be overcome, including low proportions of adults producing free-flowing gametes and asynchronous development of gametes in broodstock facilities.

- Hatchery managers estimate that the maximum capacity for State, Provincial, and Federal systems will be approximately 4.5 million fall fingerling coregonines when all planned renovations are completed. Given that preliminary estimates suggest about 8 million fingerlings might be necessary just for Green Bay, Lake Michigan, targeted restoration planning will be essential, and expectations for rate of progress need to be managed.

- There may be other source populations to consider. For example, C. kiyi are abundant in Lakes Superior and Nipigon; C. zenithicus are present, but rare in Lake Superior, and occur, but are declining, in Lake Nipigon. The C. nigripinnis occurs in Lake Nipigon and in inland Ontario lakes near Algonquin Park. The C. hoyi are found in Lakes Superior, Michigan, and Huron, although Eshenroder and others (2016) hypothesize that the Lake Huron C. hoyi form is actually a hybrid swarm.

- Workshop speakers ranked coregonine forms and their potential source populations from easiest to hardest to collect and propagate as follows: C. artedi, C. hoyi, C. kiyi, C. nigripinnis, and C. zenithicus. 


\section{Key Uncertainties (Prioritized)}

Workshop participants prioritized the following uncertainties surrounding propagation through breakout group discussion and individual voting.

1. Given coregonine plasticity, should hatchery managers mimic natural environmental conditions (for example, food, temperature, light, density, predation exposure) during rearing, and how would these conditions affect coregonine morphology and poststocking survival? To address this uncertainty, researchers would need to compile existing information (or collect new information) about those environmental conditions to which larval and juvenile $C$. hoyi and $C$. artedi are exposed in the wild. This information could be used to design experiments in "research hatcheries" (for example, USGS facilities in Tunison, Ann Arbor, Upper Midwest Environmental Science Center; the FWS Northeast Fishery Center). Response variables in these experiments could include morphology and meristics, epidemiology, growth, survival, fatty acid profiles, lipid concentrations, stress hormone levels, swimming ability, and reaction to predators. Some of these metrics could be compared to wild fish.

2. How many fish are required for stocking, and at which life stage? To address this uncertainty, researchers could use existing stock-recruit models and assumed mortality rates to determine natural densities of fall fingerlings or yearling fish from viable wild populations (for example, Lake Superior C. artedi, Lake Michigan C. hoyi). To address which life stage (for example, fall fingerlings or spring yearlings) produces higher poststocking survival, managers should carefully design studies that allow this comparison. To elaborate, stocking events should be continuously evaluated to identify characteristics associated with high survival and ensure that stocking decisions are assessed as part of an adaptive management process.

3. What are the spatial restoration units within each lake where stocking could be implemented as a restoration tool? Given the limited capacity for Great Lakes hatcheries to produce coregonines, managers recognize the value of delineating "restoration units" to organize strategic restoration planning. Supporting research here could include identification of ideal coregonine habitat for each life stage, and quantifying migration potential for coregonines (for example, ongoing acoustic telemetry work on Lake Ontario).

4. If reintroduction of C. kiyi is a priority, scientists will need to better understand its life history to guide gamete collection and hatchery rearing. Hatchery scientists and coregonine ecologists agree that little is known about C. kiyi reproduction and early life history in Lake Superior, where it is most abundant and could serve as a possible gamete source. Should managers consider C. kiyi a viable option for reintroduction in Lakes Michigan, Huron, or Ontario, research that could overcome these basic knowledge gaps should be a high priority.

Other uncertainties that were captured during Day 2 breakouts (no prioritized order):

- How can we further develop marking techniques (coded wire tags, chemicals, genetics) to differentiate hatchery-treatment groups and quantify poststocking survival?

- What are the genetic risks of stocking in lakes with small, existing populations?

- How can disease concerns, especially with respect to maintaining coregonine broodstock, be managed in hatcheries?

- Can C. kiyi or C. hoyi broodstock be successfully developed in hatcheries?

- What effect does hatchery-fish transport have on poststocking survival?

- How does poststocking survival vary among stocking locations or the time of day fish are stocked?

- What effect does sea lamprey parasitism have on survival of stocked individuals?

- Could C. nigripinnis be considered for propagation?

\section{Capacities}

Roger Gordon (FWS) estimated that long-term maximum capacity for coregonine propagation across the basin (including Federal, Provincial, State, Tribal territories was about 4.5 million fall fingerlings. FWS hatcheries have the potential to produce a considerable proportion of this capacity, but only after renovations to these facilities are complete. Projected FWS production capacities are:

- Jordan River: 2.1 million fall fingerling (mff) by 2020;

- Iron River: 1.0 mff by 2021;

- Allegeny: $0.4-0.5 \mathrm{mff}$ by 2020 ;

- Northeast Fishery Center $0.25 \mathrm{mff}$ by 2020; and

- Genoa NFH: brood production by 2017.

Other USGS and FWS facilities have the potential to provide experimental research facilities to inform large-scale propagation in the FWS hatcheries (as described in Key Uncertainty 1, above). The USGS Tunison Lab, for example, has a history of providing research support for lake trout propagation owing to the work of George Ketola (retired). More recently, it has been operating as both a research and production facility. The newly renovated USGS Ann Arbor wet lab offers another space 
where experiments could be undertaken, building on ongoing

pilot work with $C$. artedi by Wendy Stott. Additional scientific expertise in fish physiology may be needed to oversee and conduct the kinds of experiments prioritized above. Other experimental propagation labs that could be used include FWS Northeast Fishery Center, USGS Upper Midwest Environmental Science Center, FWS Midwest Fisheries Center, and USGS National Wildlife Health Center.

\section{References Cited}

Dunham, Jason, Gallo, Kirsten, Shively, Dan, Allen, Chris, and Goehring, Brad, 2011, Assessing the feasibility of native fish reintroductions: a framework applied to threatened Bull Trout: North American Journal of Fisheries Management, v. 31, no. 1, p. 106-115.

Eshenroder, R.L., Vecsei, Paul, Gorman, O.T., Yule, D.L., Pratt, T.C., Mandrak, N.E., Bunnell, D.B., and Muir, A.M., 2016, Ciscoes (Coregonus, subgenus Leucichthys) of the Laurentian Great Lakes and Lake Nipigon: Great Lakes Fishery Commission Miscellaneous Publication 2016-01, accessed May 18, 2017, at http://www.glfc.org/pubs/misc/ Ciscoes_of_the_Laurentian_Great_Lakes_and_Lake_Nipigon.pdf.

Koelz, Walter, 1929, Coregonid fishes of the Great Lakes: Bulletin of the United States Bureau of Fisheries Document 1048, p. 297-643.
Lindsey, C.C., 1981, Stocks are chameleons: plasticity in gill rakers of coregonid fishes: Canadian Journal of Fisheries and Aquatic Sciences, v. 38, no. 12, p. 1497-1506.

Todd, T.N., and Smith, G.R., 1992, A review of differentiation in Great Lakes ciscoes: Polish Archives of Hydrobiology, v. 39, no. 3-4, p. 261-267.

Turgeon, Julie, and Bernatchez, Louis, 2003, Reticulate evolution and phenotypic diversity in North American ciscoes, Coregonus spp. (Teleostei: Salmonidae): implications for the conservation of an evolutionary legacy: Conservation Genetics, v. 4, no. 1, p. 67-81.

Turgeon, Julie, Reid, S.M., Bourret, Audrey, Pratt, T.C., Reist, J.D., Muir, A.M., and Howland, K.L., 2016, Morphological and genetic variation in Cisco (Coregonus artedi) and Shortjaw Cisco (C. zenithicus): multiple origins of Shortjaw Cisco in inland lakes require a lake-specific conservation approach: Conservation Genetics, v. 17, no. 1, p. 45-56.

Vander Wal, Eric; Garant, Dany; Festa-Bianchet, Marco; Pelletier, Fanie; 2013, Evolutionary rescue in vertebrates: evidence, applications and uncertainty. Philosophical Transactions of the Royal Society B, v. 368, DOI: 10.1098/ rstb.2012.0090. 

Appendixes 1-4 


\title{
Appendix 1. Team Charter
}

\author{
Multiagency Coregonid Restoration Science Workshop Planning Team
}

June 2016

\section{Background}

At the U.S. Geological Survey (USGS) and U.S. Fish and Wildlife Service (FWS) Native Fish Restoration and Science Meeting held November 4-5, 2015, in Ann Arbor, Michigan, policymakers, managers, and scientists came together with the goal of developing a strategic Department of Interior (DOI) approach to Great Lakes native species restoration with an emphasis on coregonids. Participants worked towards understanding current efforts and unique capacities within the DOI that could support restoration of coregonids in the Great Lakes. One key outcome from the meeting was a commitment to draft a document identifying (1) relevant DOI science and propagation capacities and (2) key uncertainties impeding coregonid restoration. This document can be shared with Great Lakes fishery managers as they work through their own management priorities for coregonid restoration, helping to develop a scientifically defensible pathway forward to addressing site-specific priorities. Participants agreed on a need to bring DOI scientists together in a workshop setting to develop this document.

\section{Problem Statement/Opportunity}

Currently, there is no single comprehensive summary of the full suite of DOI science and propagation capacities that could support coregonid restoration. A comprehensive document could guide development of a common agenda for mutually reinforcing activities that address the highest priority needs of Great Lakes fishery managers relative to coregonid restoration. Key uncertainties impeding coregonid restoration were summarized by Zimmerman and Krueger (2009) but could be revised and expanded to include a propagation perspective. Recent Great Lakes Restoration Initiative funding provides financing for holding a series of science workshops to develop a Multiagency Coregonid Restoration Program once management priorities are identified. To that end, a multiagency planning committee has been identified to develop and implement these science workshops.

\section{Objectives}

The goal of the planning team is to organize the first science workshop and produce desired outputs identified during the November 4-5, 2015, meeting in Ann Arbor, Mich. Those outputs should include at minimum

- Identifying and documenting the relevant DOI science and propagation capacities.

- Identifying and documenting the key uncertainties impeding coregonid restoration.

\section{Products}

The ultimate product resulting from the first workshop will be a draft document identifying key uncertainties and DOI capacities for coregonid restoration. This draft document should prepare the DOI to take into consideration any management priorities identified during a workshop sponsored by the Council of Lake Committees in late 2016.

\section{Roles and Responsibilities}

The workshop planning team is tasked with developing the agenda, organizing and facilitating the workshop, and ensuring the identified product results. The team should plan a workshop for between 20 and 30 attendees, some of whom should be experts outside the DOI (for example, academic scientists, international scientists). To ensure that the workshop maximizes its productivity, the planning team will also develop a draft list of key subject areas relevant to coregonid restoration (for example, genetic diversity, recruitment bottlenecks) and circulate to the steering committee and attendees prior to the initial workshop. The USGS will lead the coordination of planning team work. 


\section{Team Membership}

- Membership is designed to provide representation from key DOI science and propagation expertise. This expertise will be provided from the USGS and FWS Regions 3 and 5.

- Team membership will include two members from the USGS Great Lakes Science Center, two members from FWS Region 3, and two members from the FWS Region 5.

- The following individuals have been identified by the respective agencies:

- Bo Bunnell and Solomon David (USGS),

- Chuck Bronte and Roger Gordon (FWS Region 3), and

- Mike Millard and Dimitry Gorsky (FWS Region 5).

\section{Planning Team Operations}

Planning Team Meetings.-The team will initially host a conference call within 2 weeks of receiving this charge. They will be joined on that call by a point of contact (POC) for each of their respective Bureaus and Regions. Those POCs are a subset of the participants from the USGS/FWS Native Fish Restoration and Science Meeting held November 4-5, 2015, in Ann Arbor, Mich., and includes: Kurt Newman (USGS), Mark Holey (FWS Region 3), and Bill Archambault (FWS Region 5). The goal of that call will be to clarify any questions the planning team members may have relative to their charge and to set timelines for hosting the first workshop and supporting actions. Future meetings following the initial conference call will be scheduled by the planning team.

Planning Team Communication.-The planning team will rely on their respective POCs as liaisons between themselves and the rest of the participants at the USGS/FWS Native Fish Restoration and Science Meeting held in Ann Arbor, Mich.; however, each planning team member should consider all the POCs as resources to use.

\section{References}

Zimmerman, M.S., and Krueger, C.C., 2009, An ecosystem perspective on re-establishing native deepwater fishes in the Laurentian Great Lakes: North American Journal of Fisheries Management, v. 29, p. 1352-1371. 


\section{Appendix 2. Workshop Agenda}

Department of Interior Coregonine Restoration Science Workshop-October 11-13, 2016

Weber's Inn, 3050 Jackson Rd, Ann Arbor, Michigan

\section{Day 1 Agenda, October 11, 2016}

12:30 PM Registration opens, optional box lunch.

1:00 PM Welcome, introductions, and logistics by Roy Stein, Workshop Facilitator and Professor Emeritus at Ohio State University.

\section{Theme I: Setting the Stage}

Objective: Expose participants to the rationale for a coregonine restoration workshop, expected products, and unambiguous context informed by our experiences with lake trout restoration and commensurate with management agency needs.

1:20 PM Introduction to the Coregonine Restoration Science Workshop. Bo Bunnell, USGS. (20 min presentation, 5 min questions)

1:45 PM Great Lakes Lake Trout Restoration: Lessons from Past Management. Chuck Krueger, Michigan State University. (30 min presentation, 5 min questions)

2:20 PM Rehabilitation of Coregonines Throughout the Great Lakes: Pipe Dream of Achievable Goal? John Dettmers, GLFC. (20 min presentation, 5 min questions)

2:45 PM Panel Discussion with Bunnell, Krueger, and Dettmers, facilitated by Stein.

3:05 PM Break

\section{Theme II: Coregonine Genetics}

Objective: Gain a shared understanding of (1) the leading and competing hypotheses of cisco evolution in lakes throughout North America (including the Great Lakes) and (2) the genetic implications for reintroduction efforts.

3:30 PM Evolutionary history of ciscoes: insights for restoration. Implications for source population selection. Julie Turgeon, Université Laval. (20 min talk, 5 min questions)

3:55 PM Synthesizing genetic and morphometric variation of Great Lakes ciscoes. Wendy Stott, USGS. (20 min talk, 5 min questions)

4:20 PM Panel discussion with Turgeon and Stott, facilitated by Stein.

4:40 PM Breakout groups. Discuss a common set of questions and brainstorm key uncertainties/research priorities for Themes I and II. Be prepared to share the group's two most important uncertainties during reporting out.

5:25 PM Reporting out of breakout groups, facilitated by Roy Stein. Develop and prioritize a common list of key uncertainties related to Themes I and II to inform DOI planning.

6:00 PM Networking and informal brainstorming session: Heavy hors d'oeuvres and cash bar at Weber's Inn. Food available between 6:30-9:00 PM. 


\section{Day 2 Agenda, October 12, 2016}

\section{Theme III: Coregonine Ecology}

Objective: Achieve a shared understanding of cisco distribution, abundance, form, and function. Where ciscoes (i.e., C. artedi and C. hoyi) are extant and well-studied, describe factors that are hypothesized to limit their recruitment, growth, and survival.

8:00 AM Overview and course charting for the day, Roy Stein.

8:15 AM A Synthesis of Science Uncertainties relating to Coregonine Re-establishment. Andrew Muir, GLFC. (30 min presentation, 5 min questions)

8:50 AM Recruitment dynamics of Great Lakes cisco (including deepwater ciscoes). Mark Vinson, USGS. (30 min presentation, 5 min questions)

9:25 AM What is albus? Randy Eshenroder, GLFC. (20 min presentation, 5 min questions)

9:50 AM Panel discussion with Muir, Vinson, and Eshenroder, facilitated by Stein.

10:10 AM Break

10:30 AM Breakout groups. Discuss a common set of questions and brainstorm key uncertainties/research priorities for Theme III. Be prepared to share the group's two most important uncertainties during reporting out.

11:30 AM Reporting out of breakout groups, facilitated by Roy Stein. Develop and prioritize a common list of key uncertainties related to coregonine ecology to inform DOI planning.

12:00 PM Lunch at Weber's Inn

\section{Theme IV: Propagation of Coregonus hoyi and artedi}

Objective: Gain a shared overview of coregonine stocking success elsewhere (Europe, Finland, Lake Ontario), what drove that success, and what challenges (winter collections, large-scale operations, disease issues, captive brood stocks, etc.) we face with coregonine propagation in the Great Lakes.

1:00 PM A Retrospective Analysis of International Stocking Attempts for Coregonine Restoration. Chuck Bronte, FWS. (20 min presentation, 5 min questions)

1:25 PM Logistical and genetic considerations for large-scale gamete collections for fall/winter spawning ciscoes (C. artedi and C. hoyi). Roger Gordon, FWS. (15 min presentation, 5 min questions)

1:45 PM Progress on the Development of Husbandry Techniques for C. hoyi in Support of Bi-national Efforts to Reintroduce Coregonines to the Great Lakes and Related Research Needs. Trevor Pitcher, University of Windsor, and Kevin Loftus, Ontario Ministry of Natural Resources. (15 min presentation +5 min questions $x 2$ )

2:25 PM Panel discussion Bronte, Gordon, Pitcher, Loftus, facilitated by Stein.

2:45 PM Break

3:15 PM Breakout groups. Discuss a common set of questions and brainstorm key uncertainties/research priorities for Theme IV. Be prepared to share the group's two most important uncertainties during reporting out.

4:15 PM Reporting out of breakout groups, facilitated by Roy Stein. Develop and prioritize a common list of key uncertainties related to coregonine propagation to inform DOI planning.

6:00 PM Networking and informal brainstorming session: Hors d'oeuvres and cash bar at Blue Tractor (brewery), 207 E Washington St, downtown Ann Arbor, MI. Food available between 6:00-9:00 PM. 


\section{Day 3 Agenda (DOI ONLY. Focused internal discussion on DOI capacity), October 13, 2016}

\section{Objectives for Day 3:}

1. Use the knowledge gained in each of the Day $1-2$ themes (Setting the Stage, Genetics, Ecology, Propagation) to identify and prioritize critical uncertainties that the DOI could pursue in the next five years, with recognition that this list could be modified through time (e.g., after Coregonine Management Priorities workshop in December 2016).

2. As informed by Day 1 - themes, identify and document both DOI (a) ongoing research and available hatchery capacity and (b) potential future research and enhanced hatchery capabilities to support coregonine restoration. Note that capacity includes bricks and mortar, equipment, and human capital.

3. Identify next steps and future science workshop topics.

8:00 AM Overview and course charting for the day, Roy Stein.

8:15 AM Overview presentation of DOI Coregonine Steering Committee's long-term vision for developing a DOI Restoration Plan for Coregonines that uses an adaptive management framework. Will include an overview of adaptive management (aka SHC), and explicit consideration of need for management priorities from Council of Lake Committees. Mike Millard, FWS.

8:35 AM Presentation on existing USGS capacity to support coregonine restoration, including work supported by FY16 GLRI funding. Kurt Newman.

8:55 AM Presentation on existing FWS capacity to support coregonine restoration, including work supported by FY16 GLRI funding. Roger Gordon, Chuck Bronte, Mike Millard, Dimitry Gorsky.

9:25 AM Breakout groups. Self-select into one of four Day $1-2$ themes to discuss prioritization of uncertainties, capacity of DOI agencies to conduct that relevant research, and future DOI science workshop topics.

10:15 AM Break. Coffee and snacks provided. Hotel check-out, if needed.

10:45 AM Reporting out of breakout groups, facilitated by Roy Stein.

11:30 AM Looking forward: (i) Discussion of workshop products, (ii) timeline and responsibility for completion, (iii) discussion of topics and scheduling for future workshops.

12:00 PM Meeting adjourned 


\section{Appendix 3. Workshop Participants}

Doug Aloisi, Project Leader

Genoa National Fish Hatchery (FWS), Genoa, Wis.

Doug_Aliosi (at) fws.gov

Angela Baran, Production Supervisor

Genoa National Fish Hatchery (FWS), Genoa, Wis.

angela_baran (at) fws.gov

Meredith Bartron, Geneticis

Northeast Fishery Center (FWS), Lamar, Penn.

meredith_bartron (at) fws.gov

Charles Bronte, Senior Biologist **

Green Bay Fish and Wildlife Conservation Office (FWS), New Franken, Wis.

charles_bronte (at) fws.gov

David "Bo" Bunnell, Research Fishery Biologist

Great Lakes Science Center (USGS), Ann Arbor, Mich.

dbunnell (at) usgs.gov

Solomon David, Research Scientist

Great Lakes Science Center (USGS), Ann Arbor, Mich.

solomondavid (at) gmail.com

John Dettmers, Fishery Management Program Director **

Great Lakes Fishery Commission, Ann Arbor, Mich.

jdettmers (at) glfc.org

Randy Eshenroder, Science Advisor

Great Lakes Fishery Commission, Ann Arbor, Mich.

randye (at) glfc.org

Peter Esselman, Research Fishery Biologist

Great Lakes Science Center (USGS), Ann Arbor, Mich.

pesselman (at) usgs.gov

Roger Gordon, Hatchery Manager

Jordan River National Fish Hatchery (FWS), Elmira, Mich.

roger_gordon (at) fws.gov

Owen Gorman, Research Biologist

Lake Superior Biological Station (USGS), Ashland, Wis.

otgorman (at) usgs.gov

Dimitry Gorsky, Fishery Biologist

Lower Great Lakes Fish and Wildlife Conservation Office

(FWS), Basom, N.Y.

dimitry_gorsky (at) fws.gov
Mike Hansen, Research Fishery Biologist

Hammond Bay Biological Station (USGS),

Hammond Bay, Mich.

michaelhansen (at) usgs.gov

Mark Holey, Project Leader **

Green Bay Fish and Wildlife Conservation Office (FWS),

New Franken, Wis.

mark_holey (at) fws.gov

Darryl Hondorp, Research Fishery Biologist

Great Lakes Science Center (USGS), Ann Arbor, Mich.

dhondorp (at) usgs.gov

Charles Krueger, Professor, Fisheries and Wildlife

Michigan State University, East Lansing, Mich.

kruege62 (at) anr.msu.edu

Brian Lantry, Supervisory Research Biologist

Lake Ontario Biological Station (USGS), Oswego, N.Y.

bflantry (at) usgs.gov

Stephen Lenart, Fishery Biologist

Alpena Fish and Wildlife Conservation Office (FWS),

Alpena, Mich.

stephen_lenart (at) fws.gov

Kevin Loftus, Manager Fish Culture Section

Ontario Ministry of Natural Resources and Forestry,

Peterborough, Ontario

kevin.loftus (at) ontario.ca

Chuck Madenjian, Research Fishery Biologist

Great Lakes Science Center (USGS), Ann Arbor, Mich.

cmadenjian (at) usgs.gov

Jim McKenna, Research Ecologist

Tunison Laboratory of Aquatic Science (USGS),

Cortland, N.Y.

jemckenna (at) usgs.gov

Mike Millard, Director **

Northeast Fishery Center (FWS), Lamar, Penn.

mike_millard (at) fws.gov

Josh Miller, Science Communication Liasion

Great Lakes Science Center (USGS), Ann Arbor, Mich. joshuamiller (at) usgs.gov 
Andrew Muir, Science Director **

Great Lakes Fishery Commission, Ann Arbor, Mich.

amuir (at) glfc.org

Kurt Newman, Western Branch Chief **

Great Lakes Science Center (USGS), Ann Arbor, Mich.

knewman (at) usgs.gov

Timothy O’Brien, Biological Science Laboratory Technician (Fisheries)

Great Lakes Science Center (USGS), Ann Arbor, Mich.

tiobrien (at) usgs.gov

Ken Phillips, Project Leader

La Crosse Fish Health Center (FWS), La Crosse, Wis.

kenneth_phillips (at) fws.gov

Trevor Pitcher, Associate Professor

Great Lakes Institute for Environmental Research

University of Windsor, Windsor, Ontario

tpitcher (at) uwindsor.ca

Jennifer Read, Director

University of Michigan, Water Center, Ann Arbor, Mich.

jenread (at) umich.edu

Stephen Riley, Research Fishery Biologist

Great Lakes Science Center (USGS), Ann Arbor, Mich.

sriley (at) usgs.gov

Ed Roseman, Research Fishery Biologist

Great Lakes Science Center (USGS), Ann Arbor, Mich.

eroseman (at) usgs.gov

Kurt Schilling, Hatchery Program Supervisor

Midwest Region Fisheries Program (FWS),

Bloomington, Minn.

kurt_schilling (at) fws.gov

Nicholas Starzl, Hatchery Manager

Iron River National Fish Hatchery (FWS), Iron River, Wis.

nick_starzl (at) fws.gov

Roy Stein, Professor Emeritus, Aquatic Ecology Lab

The Ohio State University, Westerville, Ohio

stein.4 (at) osu.edu
Wendylee Stott, Research Associate

Great Lakes Science Center/Michigan State Univ., Ann Arbor, Mich.

wstott (at) usgs.gov

Russ Strach, Director **

Great Lakes Science Center (USGS), Ann Arbor, Mich.

rstrach (at) usgs.gov

Thomas Todd, Retired - Fishery Research Biologist Great Lakes Science Center (USGS), Saline, Mich. gaypipes (at) aol.com

Ted Treska, Fisheries Biologist Green Bay Fish and Wildlife Conservation Office (FWS), New Franken, Wis.

ted_treska (at) fws.gov

Julie Turgeon, Associate Professor, Biology

Université Laval, Quebec City, Quebec

julie.turgeon (at) bio.ulaval.ca

Lynn Vaccaro, Research Specialist

University of Michigan, Water Center, Ann Arbor, Mich.

lvaccaro (at) umich.edu

Christopher Vandergoot, Research Fish Biologist

Lake Erie Biological Station (USGS), Huron, Ohio

christopher.vandergoot (at) gmail.com

Mark Vinson, Chief

Lake Superior Biological Station (USGS), Ashland, Wis. mvinson (at) usgs.gov

David Warner, Research Fishery Biologist

Great Lakes Science Center (USGS), Ann Arbor, Mich.

dmwarner (at) usgs.gov

Nathan Wilke, Branch Chief

Branch of Hatcheries and Applied Science (FWS),

Falls Church, Va.

nathan_wilke (at) fws.gov

Dan Yule, Fishery Research Scientist

Lake Superior Biological Station (USGS), Ashland, Wis.

dyule (at) usgs.gov 
Table 3-1. Coregonine workshop planning team.

\begin{tabular}{ll}
\hline \multicolumn{1}{c}{ Name } & \multicolumn{1}{c}{ Affiliation } \\
\hline Charles Bronte & Green Bay Fish and Wildlife Conservation Office (FWS) \\
David "Bo" Bunnell & Great Lakes Science Center (USGS) \\
Solomon David & Great Lakes Science Center (USGS) \\
Roger Gordon & Jordan River National Fish Hatchery (FWS) \\
Dimitry Gorsky & Lower Great Lakes Fish and Wildlife Conservation Office (FWS) \\
Mike Millard & Northeast Fishery Center (FWS) \\
Jennifer Read & University of Michigan, Water Center \\
Roy Stein & The Ohio State University, Aquatic Ecology Lab \\
Lynn Vaccaro & University of Michigan, Water Center \\
\hline
\end{tabular}

\section{Steering Committee}

**These workshop participants served on the steering committee for this workshop and other related efforts within the Multi-Species Coregonine Restoration Program. 


\section{Appendix 4. Summary of Participant Feedback Survey}

\section{Survey Respondents}

All workshop participants were invited to complete an online survey to provide feedback on the DOI Coregonine Restoration Science Workshop. The 41 workshop attendees (including the planning team and participating steering committee members) received 3 email messages about the survey. Twenty-one workshop participants (51 percent) completed the 12-question survey, which included 5 multiple choice and 7 open response questions. Not everyone responded to all the open response questions.

\section{Overall Effectiveness}

Overall, a large majority of participants (71-90 percent) felt the workshop achieved its four primary objectives moderately well or very well (table 4-1). Survey respondents were somewhat more positive about how well the workshop achieved two of the objectives: building understanding of relevant science and expanding professional networks.

Table 4-1. Survey question: From your perspective, how well did the workshop achieve the following objectives?

[Table shows percentage of 21 respondents]

\begin{tabular}{|c|c|c|c|c|c|}
\hline \multirow{2}{*}{ Workshop objective } & \multicolumn{5}{|c|}{ How well objectives were achieved (in percent) } \\
\hline & Very well & Moderately well & Slightly & Not at all & No opinion \\
\hline Build understanding of current coregonine restoration science & 38 & 52 & 10 & 0 & 0 \\
\hline Expand professional networks to support future collaborations & 38 & 43 & 19 & 0 & 0 \\
\hline Build understanding of different agency capacities to support restoration & 33 & 43 & 19 & 0 & 5 \\
\hline Document key uncertainties for coregonine restoration & 38 & 33 & 24 & 5 & 0 \\
\hline
\end{tabular}

\section{Themes and Presentations}

When asked to identify and comment on the most valuable workshop theme, seven people indicated "genetics," five said "ecology" and four reported "propagation." All the themes were seen to increase understanding. For example, of the 21 survey respondents, 95 percent indicated their understanding increased "moderately" or "considerably" within the propagation theme (table 2). When asked about the most valuable presentation, nine people identified Julie Turgeon's talk, five identified Andrew Muir's talk, and two said "propagation." Comments about why a particular theme or presentation was valuable included:

- "I wasn't aware of how much effort was currently being put into propagation of coregonines in the Great Lakes region."

- "I found all the themes valuable and could not single one out. They were complementary, too."

- "The ecology one should have been more expansive. I do not think the group gained a shared understanding of the ecology of these fishes."

- "The propagation theme provided a good overview of past and current efforts to propagate coregonids. Also provided good discussion on husbandry techniques being developed."

- "The coregonine ecology session was most valuable because it improved my understanding of factors that should influence the feasibility of restoration efforts and the species or forms to be used."

- "Muir integrated genetics and ecological information well in the context of restoration."

- "Julie Turgeon spoke with knowledge and conviction. She was not the typical wishy-washy genetics apologist saying that we need to keep doing genetics studies forever and ever."

- "Andrew's talk provided a lot of good background that I needed to connect the dots of the other talks."

- “Julie Turgeon's talk on evolutionary history of ciscoes has implications for source population selection. It was very informative as to the current status of the various forms within the lakes." 
Table 4-2. Survey question: To what extent did the workshop activities increase your understanding of current science and knowledge gaps within each theme?

[Table shows percentage of 21 respondents]

\begin{tabular}{lcccc}
\hline \multirow{2}{*}{ Workshop themes } & \multicolumn{4}{c}{ Degree to which understanding increased (in percent) } \\
\cline { 2 - 5 } & Considerably & Moderately & Slightly & Not at all \\
\hline Setting the stage & 50 & 30 & 20 & 0 \\
Genetics & 57 & 29 & 10 & 5 \\
Ecology & 43 & 43 & 14 & 0 \\
Propagation & 52 & 43 & 5 & 0 \\
\hline
\end{tabular}

\section{Feedback on Workshop Activities}

Participants found the presentations, evening networking events, and breaks to be most useful to them (table 4-3). The panel and large group discussions were seen as less useful than other elements. On average, participants knew about 60 percent of workshop attendees prior to the workshop and a third knew half or less of attendees. Breaks and social opportunities were well received by the group and seemed to successfully foster networking.

Table 4-3. Survey question: How useful did you find each of the workshop elements? Should there have been more or less time dedicated to any of these elements?

[Table shows percentage of 21 respondents]

\begin{tabular}{|c|c|c|c|c|c|c|c|}
\hline \multirow[b]{2}{*}{ Workshop element } & \multicolumn{4}{|c|}{ Usefulness to you } & \multicolumn{3}{|c|}{ Time schedules } \\
\hline & Very useful & Useful & $\begin{array}{c}\text { Somewhat } \\
\text { useful }\end{array}$ & $\begin{array}{c}\text { Not at all } \\
\text { useful }\end{array}$ & $\begin{array}{c}\text { More time } \\
\text { needed }\end{array}$ & Just right & $\begin{array}{c}\text { Less time } \\
\text { needed }\end{array}$ \\
\hline Presentations & 52 & 43 & 5 & 0 & 17 & 83 & 0 \\
\hline Evening events & 48 & 48 & 5 & 0 & 17 & 83 & 0 \\
\hline Breaks & 38 & 52 & 5 & 5 & 17 & 83 & 0 \\
\hline Breakout sessions & 40 & 35 & 20 & 5 & 43 & 43 & 14 \\
\hline Q\&A for speakers & 14 & 71 & 10 & 5 & 23 & 77 & 0 \\
\hline Panel discussion & 14 & 57 & 24 & 5 & 23 & 62 & 15 \\
\hline Reporting out and large group discussions & 14 & 38 & 48 & 0 & 23 & 62 & 15 \\
\hline
\end{tabular}

\section{Breakout Sessions}

Participants were generally satisfied with how time was allocated among workshop activities with one exception; many wanted more time for breakout discussions (table 4-3). When asked to comment on the way the small groups were assigned and facilitated, six people indicated a preference for more structure and clearer guidance, suggesting groups have an easel displaying exactly what was to be accomplished in the group, helping create stronger facilitation and more effective note taking. Five respondents indicated the amount of structure worked well, and one person wanted longer breakout sessions with "somewhat less structure." All survey respondents preferred assigned breakout groups to ensure a diversity of viewpoints and fostering new connections.

\section{Future Workshop Topics}

Survey respondents rated coregonine ecology, conservation planning, and propagation issues as the most important topics for future workshops (table 4-4). Importance and personal interest in attending did necessarily align. For example, a multifocus workshop was only rated as being moderately important but 69 percent of respondents indicated they would attend, making it the second most popular topic. A few other workshop topics were suggested, some of which could fit within one of the proposed topics. 
- Conservation Planning

- Further identifying restoration priorities (species, life stages, forms) for each lake

- Further examination of the relative merits of single species restoration versus restoration of function

- Coregonine Ecology

- Knowing the variety of habitats and behaviors of non-larval stages might help us target field sampling efforts

- Coregonine Propagation

- Fish health; what is known and unknown to establish key uncertainties and priorities in this arena

Table 4-4. Survey question: How important are the following topics for future workshops?

[Table shows percentage of 21 respondents for "Importance of topic" and percentage of 16 respondents for "Would you attend?"]

\begin{tabular}{|c|c|c|c|c|c|c|}
\hline \multirow{2}{*}{ Potential workshop topic } & \multicolumn{3}{|c|}{ Importance of topic } & \multicolumn{3}{|c|}{ Would you attend? } \\
\hline & High & Moderate & Low & Yes & Maybe & No \\
\hline Coregonine ecology (early life history, habitat) & 76 & 24 & 0 & 81 & 19 & 0 \\
\hline Coregonine propagation issues & 60 & 40 & 0 & 63 & 25 & 13 \\
\hline Coregonine genetics (including marker types, nomenclature) & 38 & 48 & 14 & 50 & 38 & 13 \\
\hline Fish community modeling & 19 & 67 & 14 & 44 & 19 & 38 \\
\hline Broad DOI collaboration workshop (engaging diversity of agencies) & 19 & 38 & 43 & 44 & 6 & 50 \\
\hline
\end{tabular}

\section{Workshop Scheduling}

Workshop participants generally agreed the noon-to-noon timing of a multiday workshop accommodated travel well. Several respondents suggested that a workshop like this should be longer, commenting: "meet for a minimum of 4 days"; "this could last a week or more, but this is not realistic"; "timing was fine, though a longer meeting would have been beneficial."

\section{Additional Suggestions}

Respondents provided a variety of additional comments that could influence the way any future workshops are planned. A few comments are paraphrased here.

\section{Other Topical Issues}

- More discussion is needed about

- the ecological factors that could influence the success of restoration efforts.

- the potential merits of attempting to restore populations using multiple species or forms versus restoring ecological function using a single species or form.

- the importance of how fish are cultured, reared, and stocked in determining the success of stocked of fish. 


\section{Preparation}

- One person expressed concern about the honesty of answers that could be provided on capacity questions.

- Several people noted that Roy Stein did an excellent job of moderating the workshop.

- One workshop participant observed that Fish and Wildlife Services presentations showed a high degree of communication, collaboration, and coordination. U.S. Geological Survey scientists seemed to have a "wait and see attitude" and came to the workshop to see what their agency planned or was offering.

\section{Attendance}

- A couple people suggested inviting smaller groups of more focused individuals. Reasons include, for example, reducing the number of people attending to those who can make and implement decisions.

- One workshop participant recommended inviting at least some management types (hopefully with a background in resource management) to the session. Managers sometimes hear and see things differently, and their involvement could help engage senior leaders who are not yet convinced of the case for coregonine restoration.

- One person suggested splitting up ecology and propagation, noting that hatchery folks seemed better funded and coordinated. 

For additional information contact: Director, Great Lakes Science Center U.S. Geological Survey

1451 Green Rd.

Ann Arbor, MI 48105-2907

https://www.glsc.usgs.gov/

Publishing support by:

The Madison and Pembroke Publishing Service Centers 


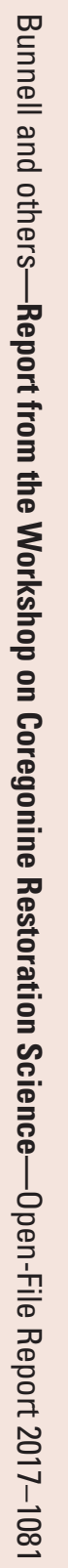

